\title{
A Study on the Key Points of Korean MPL Training System
}

\author{
Jang Ryong Lee", Moonjin Kwon", Hanjoon Kwon ${ }^{* * *+*}$
}

\begin{abstract}
Multi-crew Pilot License (MPL) is an international pilot certification adopted by the International Civil Aviation Organization (ICAO) in 2006 under the recognition of the need for efficient and systematic pilot training including the education of pilots with advanced aviation technology and ability to respond to flight environment, resolution of the human factor problems of pilots, and provision of stable training tools for transport aircraft pilots for potential risk of pilot shortage in the future. South Korea also has prepared a legal basis for operating an MPL system in the Aviation Act in 2009, but there has been no domestic MPL qualifier. The biggest reason for this seems to be the insufficient domestic MPL training system. Therefore, it is necessary to benchmark the international standards of the ICAO, and to promote the development of the Korean MPL training system through revision and supplementation of laws and regulations in consideration of Korean circumstances.
\end{abstract}

Key Words : MPL (Multi-crew Pilot License), Multi-Pilot, Competency, ATO (Approved Training Organization), FSTD (Flight Simulation Training Device)

\section{INTRODUCTION}

Development of the aviation industry has slowed down for a while due to the global COVID-19 pandemic, but we should take advantage of this period as an opportunity to prepare the growth of aviation industry. Choi et al. (2018) suggested that the continuous development of aviation industry requires securing international competitiveness to respond to unlimited demand

Received: 01. Jun. 2021, Accepted: 01. Jun. 2021

* Professor, Department. of Aeronautical Science \& Flight Operations, Korea Aerospace University Corresponding Author E-mail : jrherky@kau.ac.kr Corresponding Author address : Office 524, Main Buiding, 76 Hanggongdaehak-ro, Deogyanggu, Goyang, Gyeongi-do, Korea

** Ph.D. Candidate, Department of Aviation Management, Korea Aerospace University

*** Graduate Student for MS, Department of Aviation Management, Korea Aerospace University in the global aviation market, government support for the air transport industry, and systematic training of aviation experts [1].

Among them, training of aviation experts requires long-term planning because visible results cannot be obtained in a short period of time. This is because airlines' pilots require a long training period and a high training cost, and also airlines would have a problem that is difficult to secure sufficient pilots or to supply substitute pilots when a problem occurs [2].

The International Civil Aviation Organization (ICAO) recognized the need for efficient and systematic pilot training from the early 1980s and adopted a new international pilot certification called Multi-crew Pilot License (MPL) in 2006 [3]. The European Union Aviation Safety Agency (EASA) also introduced a European MPL based on the ICAO MPL standards and requirements in 2013, and a total of 26 countries are enforcing the MPL system as of February 2020 
[4].

Meanwhile, the South Korean government recognized the need for introducing the MPL system that was considered by the ICAO and prepared a legal basis for the operation of an MPL system in the Aviation Act in 2009 [5], but domestic MPL qualifiers have not been produced as of 2021.

The reason that MPL qualifiers have not been produced in South Korea is thought that detailed standards for the MPL training system are insufficient and the infrastructure for implementing them was inadequate.

This study aims to propose key points that need to be reflected in the Korean MPL training system through an analysis of differences between the major standards of the MPL training system suggested by international civil aviation organizations.

\section{MAIN DISCOURSE}

\subsection{MPL and Qualifier Training Overview}

The ICAO defines the MPL as a pilot qualification granted to persons who have core competencies such as knowledge, skill, and attitude that can perform standard operations during flight [6].

Meanwhile, the EASA defines MPL as a pilot qualification granted to persons who have core competencies to perform duties as a transport aircraft co-pilot, and states that applicants who want to acquire the qualification must complete competency-based training in a multi-crew environment in an approved training organization (ATO) that belongs to or is contracted with an air transport service provider [7].

\subsection{ICAO Standards about MPL Training System}

The ICAO presents the requirements and training standards for acquiring the MPL qualification through Annex 1 and Doc 9868. To obtain the qualification, the applicant must be aged 18 years or older, have Medical Fitness level 1, and aviation English speaking proficiency level 4 or higher. In addition, the applicant must have an experience of minimum of 240 hours of flight and at least 12 or more takeoffs and landings (can be reduced to 6 if the training requirements are satisfied) as pilot flying (PF) or pilot monitoring (PM) using a flight simulator and actual aircraft in an ATO. Furthermore, they must obtain knowledge of a level that is required to acquire the ATPL through a ground school for 9 subjects including aviation laws, and must have the skills and knowledge required to perform duties as co-pilots of turbine-engine aircraft operated by two pilots [8].

The training focuses on acquiring the core competencies required to obtain the MPL. The core competencies consist of 8 components: (1) Application of procedure, (2) Communication, (3) Aircraft flight path management, automation, (4) Aircraft flight path management, manual control, (5) Leadership and teamwork, (6) Problem solving and decision making, (7) Situation awareness, and (8) Workload management [9].

The training for core competencies consists of four phases from phases 1 to 4, and the key points of each training phase are listed in Table 1 [10].

The above-mentioned phased MPL training is characterized by using multiple FTSDs unlike the traditional pilot training. The ICAO requires a minimum flight time of 240 hours for MPL qualification. This criterion can be acquired through real and simulated flight experiences. The flight experience using real aircraft consists of experience required to acquire single pilot qualification in Phase 1, experience required to acquire instrument flight qualification in Phase 2 , and experience required for type rating and takeoff/landing training in Phase 4. The other flight experiences can be acquired using FTSDs. The appropriate types of FTSD that match the training objectives of each phase are specified 
Table 1. Components of MPL training program

\begin{tabular}{c|c|l}
\hline \multicolumn{2}{c|}{ Phase } & \multicolumn{1}{c}{ Main contents } \\
\hline Phase 1 & $\begin{array}{c}\text { Core flying } \\
\text { skills } \\
\text { training }\end{array}$ & $\begin{array}{l}\text { Training to acquire single } \\
\text { pilot competency / } \\
\text { qualification }\end{array}$ \\
\hline Phase 2 & $\begin{array}{c}\text { Basic } \\
\text { training }\end{array}$ & $\begin{array}{l}\text { Introduction to multi-crew } \\
\text { operation and instrument } \\
\text { flight }\end{array}$ \\
\hline Phase 3 & $\begin{array}{c}\text { Intermediate } \\
\text { training }\end{array}$ & $\begin{array}{l}\text { Cultivation of competency } \\
\text { for multi-crew operation in a } \\
\text { high-performance, } \\
\text { multi-engine turbine aircraft }\end{array}$ \\
\hline Phase 4 & $\begin{array}{l}\text { Advanced } \\
\text { training }\end{array}$ & $\begin{array}{l}\text { Training to adapt to the } \\
\text { airline operation environment } \\
\text { using an aircraft of the same } \\
\text { type as the limited aircraft } \\
\text { for which to acquire license } \\
\text { or using a FTSD }\end{array}$ \\
\hline
\end{tabular}

as shown in Table 2 below [11].

The knowledge and skills acquired through training can be verified through multiple testings of whether the person has core competencies for performing standard operations as a multi-crew pilot.

\subsection{Domestic Standards Related to MPL Qualification}

The law that prescribes the pilot qualification in South Korea is the Aviation Safety Act. The scope of the duties for 'co-pilot' qualification is specified as acts that can be performed by a qualified private pilot and the acts of operating

Table 2. MPL training aircraft and FSTDs

\begin{tabular}{c|l}
\hline Phase & \multicolumn{1}{|c}{ Aircraft and training equipment } \\
\hline \multirow{2}{*}{ Phase 1 } & Aeroplane : Single or multi-engine \\
\cline { 2 - 2 } & FSTD: Type I \\
\hline \multirow{2}{*}{ Phase 2 } & Aeroplane : Single or multi-engine \\
\cline { 2 - 2 } & FSTD: Type IV \\
\hline \multirow{2}{*}{ Phase 3 } & FSTD: Type VI \\
\hline \multirow{2}{*}{ Phase 4 } & $\begin{array}{l}\text { Aeroplane : Turbine, multi-engine, } \\
\text { Multi-crew certified }\end{array}$ \\
\cline { 2 - 2 } & FSTD: Type VII \\
\hline
\end{tabular}

an aircraft as a pilot other than the captain [12].

The detailed conditions for pilot qualification are defined in terms of qualifications, knowledge and flying skills through the standards for operating technology for fixed-wing aircraft [13] . Regarding the qualification requirements of 'co-pilot', most of the ambiguity of qualification requirements compared to airline transport/ commercial/private pilot is not clarified.

For example, the following conditions are specified for 'co-pilot' qualification.

Person who can read, speak, write, and understand Korean or English

Person who has passed an exam about aviation knowledge

Person who satisfies the flight experience conditions defined in Annex 4 of the Enforcement Rule of the Aviation Safety Act.

Person who has passed the practical exam for the flight field corresponding to the qualification to be acquired

Among the above requirements, the flight $\mathrm{ex}^{-}$ perience requirement specified in Annex 4 of the Enforcement Rule of the Aviation Safety Act are as follows.

a) Completion of a training course in a professional educational institution

b) Person having a total flight experience of flight for more than 240 hours including the flight training time using a flight simulator and the actual flight time using a real flight. In this case, the flight time using a real aircraft must be at least 40 hours.

\subsection{Comparison between ICAO MPL Training Standards and Domestic Standards}

When the ICAO standards related to MPL training are compared with the standards specified in domestic laws, the following major differences were identified.

First, the ICAO requires aviation English proficiency level 4 or higher for one of MPL quali- 
fication conditions, but in South Korea, it is prescribed that the applicant must be able to read, speak, write and understand English.

Second, the ICAO requires a level of knowledge for acquiring the ATPL in order to obtain the MPL and ask the applicant to receive tests of 9 subjects including aviation laws. However, in Korea, only the aviation regulations are required as the exam subjects and scopes for 'co-pilot' qualification.

Third, the ICAO MPL training standards specify that the most important flying skill that the applicant must have is the ability to perform the flight mission as a 'co-pilot' of a turbineengine aircraft operated by two pilots. However, there is no related domestic regulations. Furthermore, the ICAO clearly stated the core competencies that need to be acquired through MPL training as 8 items including the application of Knowledge, but the core competencies in South Korea are not clear.

Fourth, the ICAO classifies MPL training into four phases including core flying skills training and defines the key points and characteristics of training in each phase. However, the Korean MPL training standards do not have guidelines for them.

Fifth, one characteristic of MPL training is that the standards for the levels and performance of FTSD required in each phase are presented because they use FTSDs such as simulators in almost every training phase, but in South Korea, there are no related standards yet.

Sixth, the ICAO allows MPL training only when it is contracted with an ATO that belongs to or contracted with an approved air transport service provider. The reason for this is that this training reflects the philosophy and operation standards of the airline that needs MPL qualifiers. Therefore, the relationship between the airline that wants to recruit MPL qualifiers and the ATO should be reflected in the designation standards for training institutes in South Korea as well.

\section{CONCLUSION}

The MPL system was born by the spread of international awareness about the need for efficient and systematic pilot training including the efficient training of pilots who have the ability to respond to advanced aircraft technologies, solution of the human factors of pilots such as teamwork problem, which are a major cause of transport aircraft accidents, and the preparation of stable transport aircraft pilot training tools for potential insufficiency of pilots in the future.

In 2006, the ICAO adopted MPL as an international pilot certification. South Korea also prepared a legal basis for operating the MPL system in the Aviation Act in 2009, but a domestic MPL qualifier has not been produced yet. The major reason that qualifiers are not produced is the lack of detailed standards about the development of a domestic MPL training system and the poor infrastructure for implementing the system.

Therefore, South Korea also needs to benchmark international standards such as the ICAO Annex and promote the development of the Korean MPL training system by supplementing the laws and related standards in consideration of domestic circumstances. As shown in this study, these standards should include the knowledge and flying skills of the applicant that needs to be achieved through MPL training, training goals, core competencies, training stage, the operation FTSD, and the accreditation criteria for approved training organization (ATO).

If the Korean MPL training system is developed through this effort, flight training restrictions and environmental problems (noise, $\mathrm{CO}_{2}$ ) due to small airspace and adverse weather conditions will be alleviated, the outflow of manpower and budget to other overseas training institutions due to restrictions on domestic flight training can be reduced, and applicants can minimize the cost of simply accumulating flight time to 
satisfy the requirements to join an airline. Furthermore, the Korean MPL training system will contribute to stable supply of pilots with competencies needed by airlines.

\section{Acknowledgment}

Part of this paper was published in the 2021 spring conference of the Korean Society for Aeronautical and Flight Operation and it has been revised and supplemented the contents.

\section{References}

1. Choi, D. H., and Hwang, H. W., "Present status of domestic air transport industry and policy proposal for national carrier's sustainable development", The Korean Journal of Air \& Space Law and Policy, 33(2), 2018, Korea Society of Air \& Space Law and Policy, p.4.

2. Kim, H. J., "The characteristics of pilot's labor market and training plan”, Master's Degree, Korea Aerospace University, Seoul, Feb 2009.

3. ICAO Annex 1, "Personnel licensing, Montreal, Canada: International Civil Aviation Organization”, 2018, p.xiii.

4. IATA, "MPL Global Course Tracker". https:// www.iata.org/contentassets/c0f61fc821dc4f6 2bb6441d7abedb076/mpl-courses-global-tra cker.xlsx

5. Public Notice of Ministry of Land, "Transport and Maritime Affairs No.2009-885", Certifica- tion of Competence of Airman/Airwoman Examination Outline Amendment.

6. ICAO Doc 9868, "Training, Montreal, Canada: International Civil Aviation Organization”, 2016.

7. EASA, "Easy Access Rules for Flight Crew Licensing(Part-FCL), Cologne, Germany: European Union Aviation Safety Agency", 2020.

8. ICAO Annex 1, "Personnel licensing, Montreal, Canada: International Civil Aviation Organization”, 2018, pp.2-21.

9. ICAO Doc 9995, "Manual of Evidence-based Training, Montreal, Canada: International Civil Aviation Organization”, 2013.

10. ICAO Doc 9868, "Training, Montreal, Canada: International Civil Aviation Organization", 2016, pp.II-1-1 App 2-1.

11. ICAO Doc 9625, "Manual of Criteria for the Qualification of Flight Simulation Training Devices, Montreal, Canada: International Civil Aviation Organization”, 2015, p.I-App.B-1.

12. MOLIT, Aviation Safety Law, Sejong: Ministry of Land, Infrastructure, and Transportation, 2020.

13. MOLIT, Notification 2017-397, Flight Operations Standards for Fixed Wing Airplane, Sejong: Ministry of Land, Infrastructure, and Transportation, 2017.

14. Lee, J. R., "A study on comparison between international MPL training standards and domestic training environment" Journal of The Korean Society for Aviation and Aeronautics, 2021 Spring Online Conference, 2021. 